\title{
AVALIAÇÃO EM GENÓTIPOS DE AMENDOIM TIPO RUNNER VISANDO A COLHEITA ANTECIPADA
}

Kennedy Brunno de Brito Martins ${ }^{1}$; Tais de Moraes Falleiro Suassuna ${ }^{2}$; Jair Heuert ${ }^{3}$; Rodolfo Pires Ribeiro $^{4}$; Juan H. Soave ${ }^{5}$, Leandro Cesar Cusim dos Santos ${ }^{6}$

${ }^{1}$ Estudante de Biologia da Faculdade Araguaia, Goiânia-GO, kennedybrunno22@gmail.com; ${ }^{2}$ Pesquisadora da Embrapa, Santo Antônio de Goiás-GO tais.suassuna@embrapa.br; ${ }^{3}$ Engenheiro Agrônomo, Técnico da Embrapa, jair.heuert@embrapa.br; ${ }^{4}$ Engenheiro Agrônomo, Beatrice Comércio Importação e Exportação de Amendoim Ltda., Tupã-SP; ${ }^{5}$ Engenheiro Agrônomo, Criadeiro El Carmen, Gral. Cabrera, Córdoba, Argentina; ${ }^{6}$ Engenheiro Agrônomo, El Carmen Sementes do Brasil, Tupã-SP.

RESUMO: Variedades de amendoim de ciclo reduzidosão demandadas para o uso em áreas de renovação de canavial. No entanto, a avaliação da maturação pelo método da raspagem do exocarpo é pouco precisa para a precocidade em condições experimentais. $\mathrm{O}$ ensaio foi conduzido em Tupã-SP na região da Alta Paulista, com 14 genótipos distribuídos em blocos completamente casualizados, com quatro repetições. As parcelas formadas por 2 linhas de 3 metros de comprimento, com espaço entre linhas de $0,9 \mathrm{~m}$ e 17 plantas por metro. O experimento foi colhido aos 127 dias após semeadura. Para a avaliação foi retirada uma amostra de 200 gramas de grãos inteiros do peso total de cada parcela, que foi classificada em grãos maduros e imaturos, e posteriormente determinada a massa de grãos maduros. Foi observado que os genótipos JS 21406, EC 98 AO, 13-413 OL, 15-265 OL e Granoleico alcançaram maior peso de grãos maduros. Já a cultivar IAC 503 e as linhagens 16-904 OL e a 13-374 OL apresentaram a menor porcentagem de maduros, indicando que não haviam atingido a maturidade para colheita aos 127 dias após a semeadura.

Palavras chaves: Arachis hypogaea L, colheita precoce, grãos maduros e produtividade.

\section{INTRODUÇÃO}

O amendoim (Arachis hypogaea L.) está em destaque no cenário atual de grãos, onde apresenta papel fundamental em áreas de rotação de canaviais (COSTA et al., 2017). Neste contexto, existe a necessidade de cultivares com o ciclo reduzido, devido ao fato de que há pouco tempo disponível para o plantio do canavial após a colheita do amendoim, em meados de março (SANTOS et al., 2017).

Determinar o início da colheita é fundamental para que se atinja a maior produtividade, pois o amendoim apresenta crescimento indeterminado e vários estágios de maturação dos grãos ao final do ciclo (SANTOS et al., 2013). Quando a colheita é realizada prematuramente, pode acarretar prejuízos 
para as indústrias e produtores; quando a colheita é realizada tardiamente, há perdas pela deterioração do pedúnculo pela idade das vagens (SANTOS et al., 2013).

O método mais usual para determinar a maturação do amendoim consiste na raspagem do exocarpo da vagem utilizando-se um jato de agua sob pressão, expondo o a coloração do mesocarpo e sendo classificado de acordo com a coloração (WILLIAMS; DREXLER, 1981). Porém essa metodologia aplicada usualmente requer grande mão de obra, pois uma vez eliminado o exocarpo deve-se fazer a avaliação rapidamente devido à mudança de coloração pelo processo. Já (SANTOS et. al., 2017) não recomendam esse método para comparar genótipos, pois não há precisão nos resultados. Pensando nisso, este trabalho se baseou na técnica proposta por (RUCKER et al., 1994), que classifica os grãos em maduros e imaturos. Aplicou-se essa técnica para avaliar este ensaio com linhagens do programa de melhoramento da Embrapa, duas variedades do Instituto Agronômico de Campinas e uma linhagem e duas variedades da El Carmen Sementes.

\section{MATERIAIS E MÉTODOS}

O experimento foi composto por 14 genótipos dispostos em blocos completos casualizados, com quatro repetições e as parcelas formadas por duas linhas de 3 metros de comprimento, com espaço entre linhas de $0,9 \mathrm{~m}$ e 17 plantas por metro. O ensaio foi conduzido em Tupã-SP na região da Alta Paulista, sendo semeado no dia 05 de dezembro de 2017 e invertido aos 127 dias. Para a avaliação foi retirada uma amostra de $200 \mathrm{~g}$ de grãos inteiros do peso total de cada parcela onde os principais critérios para a avaliação foram a presença ou ausência da rugosidade nos grãos, e também foi avaliado a massa de 100 grãos de cada genótipo.
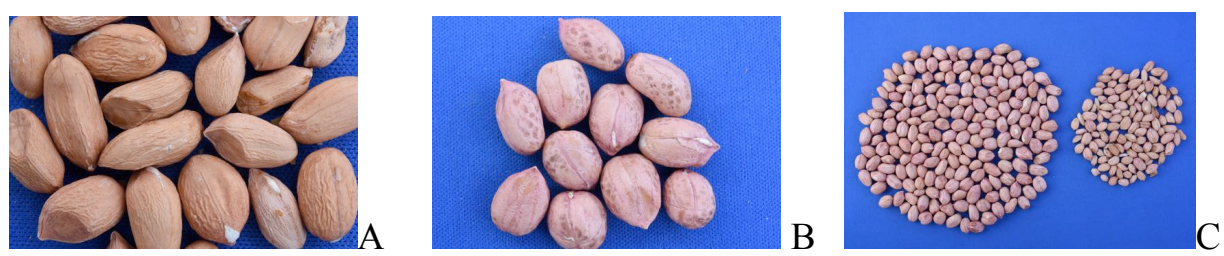

Figura 1: (A) Grãos com rugosidade devido a colheita prematura, (B) Grãos maduros sem rugosidade, (C) Comparação entre grãos com rugosidade e sem rugosidade.

Os resultados obtidos foram submetidos às análises de variância usando o programa SISVAR 5.6. O teste de médias empregado foi Skott-Knott, a 5\% de probabilidade.

\section{RESULTADOS E DISCUSSÃO}

Houve diferença estatística entre os genótipos para as duas variáveis avaliadas (Tabela 1). Os genótipos com maior percentagem de grãos maduros foram JS 21406 com 94,9 \%, EC 98 AO, 92,4 \%, 13-413 OL, 89,9 \%, 15-265 OL, 88,8 \% e Granoleico, 88,6 \%. Essa porcentagem de grãos maduros 
indica que estes genótipos possuem alta capacidade adaptativa e tiveram um bom desenvolvimento num cultivo com colheita antecipada.

Os genótipos com menor percentagem de grãos maduros foram IAC 503, 61,9 \%, 16-904 OL, 59,6\% e a 13-374 OL com 51,8 \%. Estes genótipos não alcançaram a maturação dos grãos o suficiente para colheita aos 127 dias, tão logo podemos observar que são materiais que precisariam de uns dias a mais para completar o ciclo e atingirem um grau de maturação mais adequado.

$\mathrm{Na}$ Argentina, foi percebido que a variedade EC 98 AO tem um ciclo de 5 dias mais curto que a variedade Granoleico, (SOAVE et al., 2013). Pode ser observado neste ensaio uma diferença, sendo a EC 98 AO com 92,4 \% e a variedade Granoleico com 88,6\% de maturação. A cultivar IAC 503 foi descrita como de ciclo longo, de 130 a 140 dias, podendo chegar facilmente a 150 dias, e a IAC OL 3, que é de ciclo de 130 dias (GODOY et al., 2017). Observando os resultados da tabela 1, podemos perceber que a IAC OL 3 com 86,6 \% de grãos maduros e a IAC 503 com 61,9\% de grãos maduros, mostrando que os resultados desta avaliação são semelhantes aos relatados anteriormente.

Tabela 1 - Avaliação de genótipos de amendoim em Tupã-SP; safra 2017-18.

\begin{tabular}{|c|c|c|c|}
\hline Genótipo & $\begin{array}{c}\text { Peso 100 } \\
\text { Grãos (g) }\end{array}$ & $\begin{array}{c}\text { Peso dos Grãos } \\
\text { Maduros }\end{array}$ & $\begin{array}{c}\text { Porcentagem de Grãos } \\
\text { Maduros (\%) }\end{array}$ \\
\hline JS 21406 & $89,65 \mathrm{a}$ & $189,0 \mathrm{a}$ & 94,9 \\
\hline EC 98 AO & $84,95 \mathrm{~b}$ & $184,8 \mathrm{a}$ & 92,4 \\
\hline $13-413 \mathrm{OL}$ & $79,10 \mathrm{~d}$ & $179,9 \mathrm{a}$ & 89,9 \\
\hline $15-265 \mathrm{OL}$ & $78,17 \mathrm{e}$ & $177,7 \mathrm{a}$ & 88,8 \\
\hline Granoleico & $77,75 \mathrm{e}$ & $177,2 \mathrm{a}$ & 88,6 \\
\hline IAC OL 3 & $77,07 \mathrm{e}$ & $173,3 \mathrm{~b}$ & 86,6 \\
\hline $15-505 \mathrm{OL}$ & $76,42 \mathrm{f}$ & $165,7 \mathrm{~b}$ & 82,9 \\
\hline $13-425 \mathrm{OL}$ & $75,57 \mathrm{f}$ & $165,7 \mathrm{~b}$ & 82,8 \\
\hline $16-822 \mathrm{OL}$ & $74,52 \mathrm{f}$ & $164,0 \mathrm{~b}$ & 82,0 \\
\hline $15-495 \mathrm{OL}$ & $82,35 \mathrm{c}$ & $141,3 \mathrm{c}$ & 70,6 \\
\hline $15-381 \mathrm{OL}$ & $79,67 \mathrm{~d}$ & $139,0 \mathrm{c}$ & 69,5 \\
\hline IAC 503 & $89,10 \mathrm{a}$ & $123,9 \mathrm{~d}$ & 61,9 \\
\hline $16-904 \mathrm{OL}$ & $75,30 \mathrm{f}$ & $119,3 \mathrm{~d}$ & 59,6 \\
\hline $13-374 \mathrm{OL}$ & $88,05 \mathrm{a}$ & $103,6 \mathrm{e}$ & 51,8 \\
\hline Média & 79,85 & 155,0 & - \\
\hline $\mathrm{CV}(\%)^{(1)}$ & 1,49 & 6,51 & - \\
\hline$F^{(2)}$ & $65,82^{*}$ & $27,80^{*}$ & - \\
\hline
\end{tabular}


Quanto ao peso de 100 grãos, foi observado que os genótipos que apresentaram maior tamanho da semente foram JS 21406 com 89,65g, seguido da IAC 503, 13-374 OL e a 15-495 OL apresentando $89,10 \mathrm{~g}, 88,5 \mathrm{~g}$, e 82,35g respectivamente. Já os outros genótipos variaram de 79,10g na 13-413 OL até 74,52g na linhagem 16-882 OL. Todos os genótipos podem se adequar a distintos mercados (Tabela 1).

\section{CONCLUSÃO}

Os genótipos JS 21406, EC 98 AO, 13-413 OL, 15-265 OL e Granoleico tiveram maiores médias de massa de grãos maduros, confirmando que estava com maturação adequada para arranquio aos 127 dias.

Os genótipos que apresentaram menor massa de grãos maduros foram IAC 503, 16-904 OL e 13-374 OL, indicando que precisariam mais alguns dias antes da inversão para alcançarem o ponto de maturação adequado para a colheita.

\section{REFERÊNCIAS BIBLIOGRÁFICAS}

COSTA, L.C.; SUASSUNA, T.M.F.; HEUERT, J.; MARTINS, K.B.B.; BARBIERI, A.L.; SILVA, W.C. Precocidade de linhagens de amendoim tipo runner em goiás. Disponível em: https://proceedings.science/encontro-amendoim-2017/trabalhos/precocidade-de-linhagens-deamendoim-tipo-runner-em-goias. Acesso em: 27 de junho de 2018.

GODOY, I.J.; SANTOS, J.F.; MORAES, A.R.A.; CARVALHO, C.L.; BOLONHEZI, D.; MICHELOTTO, M.D.; FINOTO, E.L.; MARTINS, A.L.M.; FREITAS, R.; CAVICHIOLI, J.C. Cultivares de amendoim IAC Alto Oleicos. Disponível em: http://infoamendoim.com.br/site/cultivares-de-amendoim-iac-alto-oleicos/. Acesso em: 27 de junho de 2018.

WILLIAMS, E. J.; DREXLER, J. S.A. Non-destructive method for determining peanut pod maturity. Peanut Science, v. 8, p. 134-141, 1981.

RUCKER, K. S.; KVIEN, C. C. K.; VELLIDIS, G.; HILL, N. S.; SHARPE, J. K. A visualmethod of determining maturity of shelled peanuts. Peanut Science, v.21, p.143-146, 1994.

Santos, E.P.; Silva, R.P.; Bertonha, R.S.; Noronha, R.H.F.; Cristiano Z. Produtividade e perdas de amendoim em cinco diferentes datas de arranquio. Disponível em: http://www.scielo.br/pdf/rca/v44n4/05.pdf. Acesso em: 27 de junho de 2018.

SANTOS, J.F.; GODOY, I.J.; MORAES, A.R.A. Métodos de avaliação de maturação de linhagens de amendoim em colheita antecipada. Disponível em: https://proceedings.science/encontro-amendoim2017/trabalhos/metodos-de-avaliacao-de-maturacao-de-linhagens-de-amendoim-em-colheitaantecipada?lang=pt-br. Acesso em: 27 de junho de 2018. 
16 e 17 de agosto de 2018, centro de convenções da FCAV/UNESP - Câmpus de Jaboticabal, SP

SOAVE, J.; ODDINO, C.; BIANCO, C.; SOAVE, S.; MORESI, A.; BUTELER, M.; TORRE, D.; FAUSTINELLI, P.; EC-98 (AO): NUEVA VARIEDAD DE MANÍ CON TOLERANCIA A SEQUIA. Jornada Del Mani, disponível em: https://www.criaderoelcarmen.com.ar/investigaciones/EC98\%20 AO\%20-\%20JNM\%202013.pdf. Acesso em: 25 de junho de 2018. 